\title{
Adenda a «Fuentes y función de la Doctrina cristiana de Miguel de Santiago para el convento de San Francisco de Quito»
}

\section{Addenda to «Sources and Function of the Christian Doctrine of Miguel de Santiago for the convent of San Francisco de Quito»}

\section{Rafael Zafra Molina}

http://orcid.org/0000-0002-3144-7222

Universidad de Navarra, GRISO

ESPAÑA

rzafra@unav.es

[Hipogrifo, (issn: 2328-1308), 9.1, 2021, pp. 1337-1359]

Recibido: 16-04-2021 / Aceptado: 26-05-2021

DOl: http://dx.doi.org/10.13035/H.2021.09.01.72

Resumen: Este artículo vuelve a estudiar la Doctrina cristiana de Miguel de Santiago a partir de la reciente publicación de la fuente grabada en la que está basada: la serie de grabados Harmonia seu concordancia Decalogi cum Oratione Dominicali... de Matias Greuter. Después de prestar especial atención a los textos de las cartelas de estas estampas, el estudio reafirma la validez del análisis iconografico-doctrinal del primer artículo y reafirma la vinculación de ambas series con la tradición de las siete septenas.

Palabras clave. Doctrina cristiana; Siete Septenas; Matias Greuter; Miguel de Santiago.

Abstract: This article re-studies the Christian Doctrine of Miguel de Santiago from the recent publication of the main source on which it is based: the series of engravings Harmonia seu concordance Decalogi cum Oratione Dominicali... by Matias Greuter. After paying special attention to the texts of the cartouches of these prints, the study reaffirms the validity of the iconographic-doctrinal analysis of the first article and reaffirms the relation of both series with the tradition of the seven septenas.

Keywords: Christian doctrine; Septem Septenas; Matias Greuter; Miguel de Santiago. 


\section{INTRODUCCIÓN}

En el número 9.1 de 2020 de esta misma revista, publiqué un artículo en el que intentaba fundamentar el empleo para la instrucción religiosa de la Doctrina cristiana de Miguel de Santiago del convento de San Francisco de Quito, analizando las fuentes en la que está basada, especialmente los catecismos ilustrados. También intentaba mostrar cómo esta obra cumbre del arte de la Contrarreforma es un ejemplo concreto en la América colonial del empleo de las imágenes para la enseñanza de la doctrina, habitual en la Iglesia tridentina.

Unos meses después de la publicación de mi artículo, apareció en la página web del proyecto PESSCA (Project on the Engraved Sources of Spanish Colonial Art), dirigido por Almerindo E. Ojeda, una entrada con el título The Christian Doctrine of Miguel de Santiago, en la que se publicaba la fuente grabada directa de esta obra. ${ }^{1}$ Se trata en concreto de la Harmonia seu concordancia Decalogi cum Oratione Dominicali cuius vii peticiones procedunt ex vii virtutibus obtinentur per vii Ecclesiae Sacramenta contra vii Peccata Mortalia iunguntur vii Spiritus Sancti Dona et vii Misericordia Opera, formada por ocho grabados de Matias Greuter y publicada por Giovanni Battista Rossi en Roma en 1653. Existen muy pocas copias además de la mencionada en PESSCA, que es la que se conserva en el Museo Albertina de Viena².

Una simple comparación de los grabados con los cuadros permite apreciar inmediatamente que los segundos (fig. 1a) no son sino copias directas de los primeros (fig. 1b), en las que se han introducido pequeñas variantes para adaptarlos a su uso local en la didáctica ${ }^{3}$. Los grabados, además, incluyen unas cartelas explicativas que declaran su contenido y que, por tanto, ayudan enormemente entender el sentido de los cuadros que carecían de ellas.

La aparición de tales grabados hace necesario volver sobre mi trabajo con esta adenda para aclarar la relación que tienen estos grabados con las fuentes en las que establecí se basan los cuadros de Miguel de Santiago, y que, si eran correctas, también tienen que serlo para esta serie de Matias Greuter.

La parte de mi artículo referida a la catequesis en Ecuador -especialmente en el convento de San Francisco de Quito- y al empleo de los citados cuadros -y sus copias de Cuenca- para la enseñanza de la doctrina no se ve enriquecida por este nuevo análisis. Por ello dejo aquí esta cuestión de lado para centrarme en el estudio de estos grabados, especialmente en las cartelas, y en lo que implican para la correcta interpretación de los cuadros y su función catequética.

1 Se trata en concreto de la Gallery 15: The Christian Doctrine of Miguel de Santiago, https://colonialart.org/galleries/gallery-15-the-christian-doctrine-of-miguel-de-santiago\#c5282a-5282b, publicada el 15 y revisada 26 de de julio de 2020. Se puede consultar una versión en pdf, firmada por Almerindo E. Ojeda en https://sites.google.com/view/arthistoryojeda.

2 Signaturas D/I/43/11 a D/I/43/11. Agradezco al Museo de la Albertina la autorización para reproducirlos en este trabajo.

3 Como señalé en Zafra, 2020, p. 1614, las variaciones entre los cuadros quiteños y los, probablemente más tardíos, de Cuenca se deben a su encargo para la catequesis por parte de dos ordenes distintas: franciscanos y carmelitas respectivamente. Esta adaptación explica también las diferencias entre estas series pictóricas y la grabada en la que están basadas. 
Fig 1a. Miguel de Santiago, Doctrina cristiana, convento de San Francisco, Quito, c. 1670.
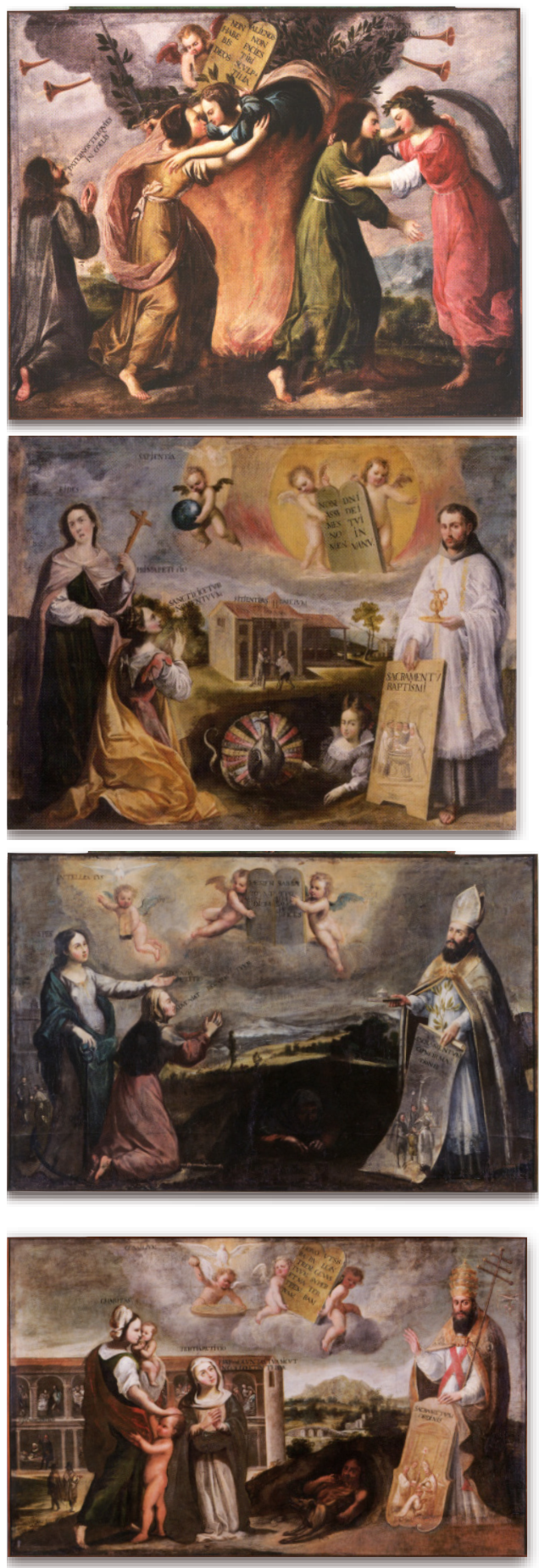

Fig 1b. Matias Greuter, Harmonia seu concordancia Decalogi, Roma, Rossi, 1653.
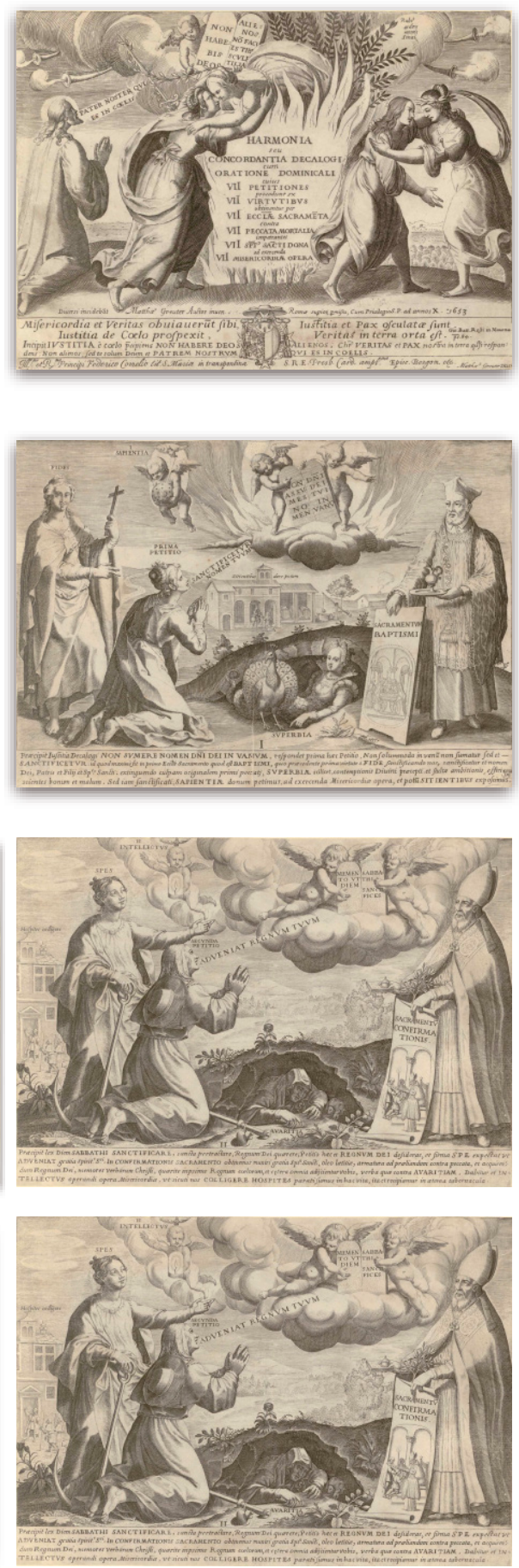
Fig 1a. Miguel de Santiago, Doctrina cristiana, convento de San Francisco, Quito, c. 1570.
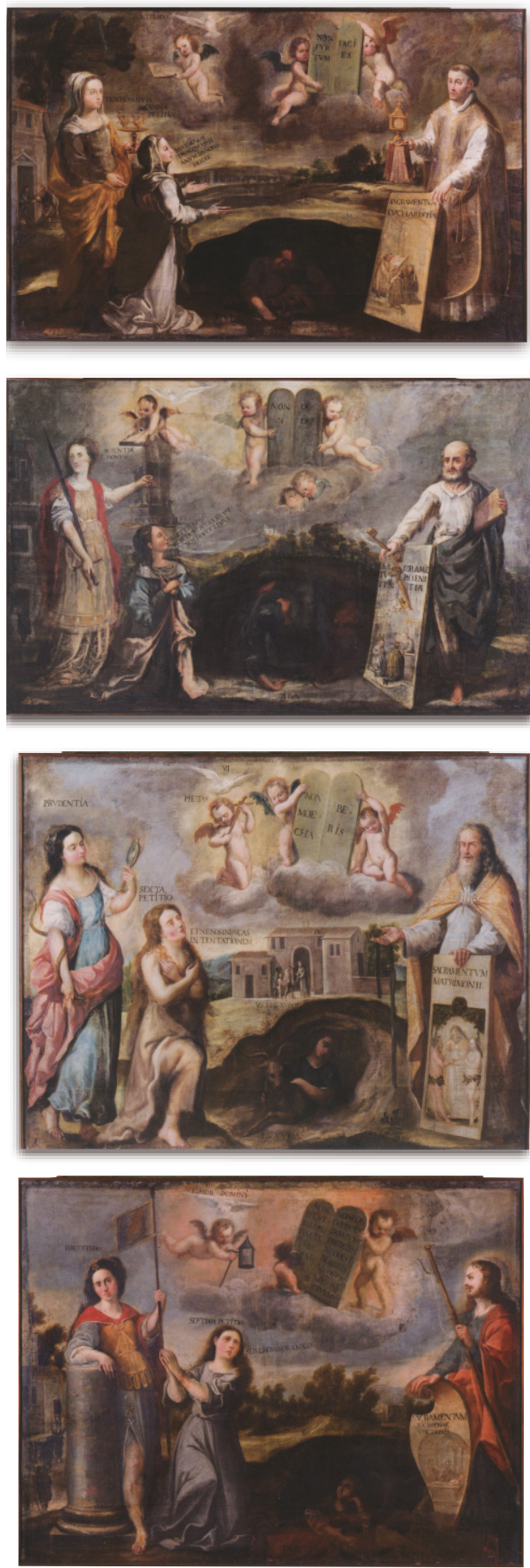

Fig 1b. Matias Greuter, Harmonia seu concordancia Decalogi, Roma, Rossi, 1653.
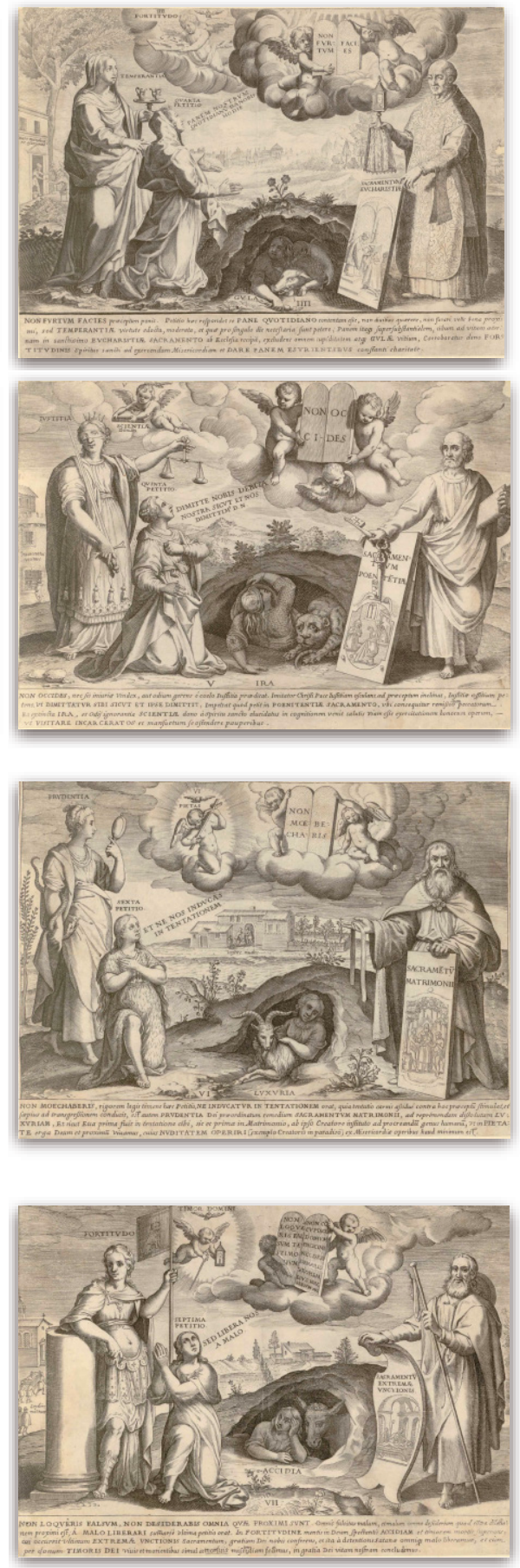

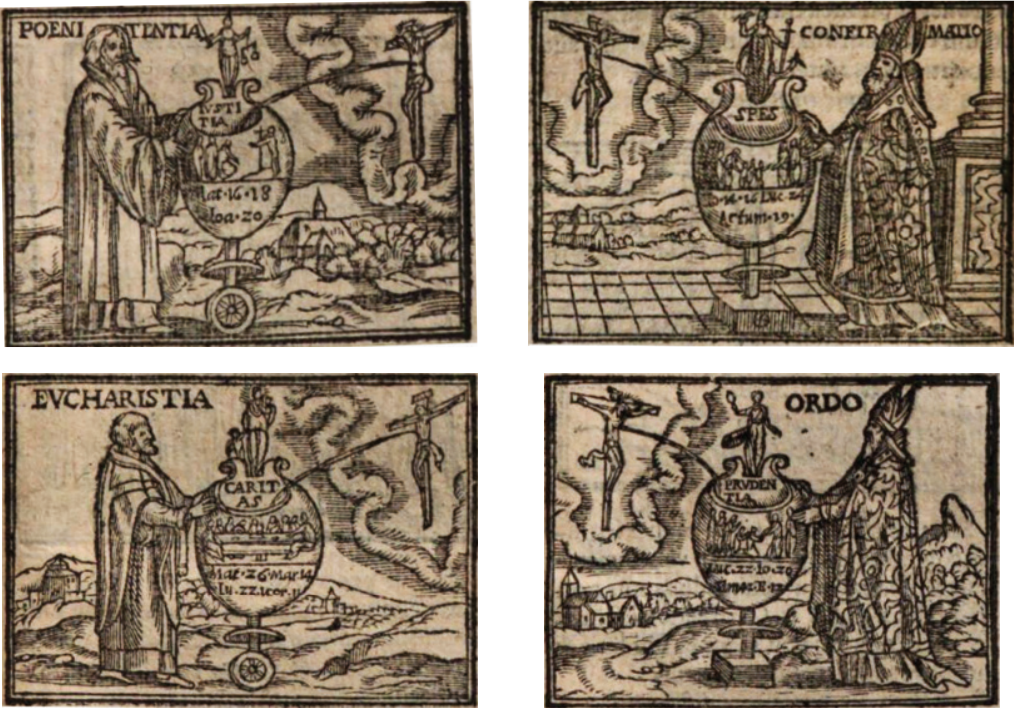

Figura 6. Grabados de sacramentos en el Canisio de Amberes, Belleri, 1575.

Dada la práctica identidad entre las obras de Miguel de Santiago y lo impreso por Greuter, el análisis iconográfico-doctrinal que hice de las primeros es igualmente válido para los segundos, por lo que no es necesario volver a repetirlo. Es suficiente con observar las imágenes para comprobarlo.

Por ejemplo, si se comparan los grabados de los sacramentos de la edición del catecismo de Canisio editado por Belleri -Amberes, 15754- con los de Greuter, sigue siendo válido lo que afirmé para los cuadros de De Santiago:

El contenido de los grabados, su composición, las cartelas aclaratorias y las escenas y relaciones conceptuales, tienen un parecido tal con la serie de Miguel de Santiago [léase aquí Greuter] que permite afirmar que quien diseño ésta conocía o tenía delante el catecismo de Belleri. A partir de la base doctrinal de estos grabados -un sacramento y una virtud - fue añadiendo sucesivamente artículos de otras secciones de la doctrina, siguiendo en lo fundamental el esquema de las siete septenas. Pese a la mayor complicación de la serie de cuadros, [grabados] todavía a simple vista se puede apreciar un parecido básico con los grabados, especialmente en las figuras de los ministros y carteles del primer plano.

Los textos de las cartelas inferiores de los grabados, suprimidas en los cuadros, permiten apreciar de modo aun más claro la estrecha vinculación de ambas series con la tradición de las siete septenas, de la que pueden considerarse dos manifestaciones más. Por ello voy a traducirlos en esta adenda, destacando lo que puedan añadir o confirmar en relación con mi primer trabajo.

4 En Zafra, 2020 y en la edición que hice de la Doctrina cristiana de Canisio, siguiendo la de Streicher 1933, consideraba la edición de 1578 como la primera edición ilustrada realizada por Belleri, señalando la existencia de un único ejemplar. Sin embargo posteriormente he localizado otra de 1575 de la que existen varios ejemplares y que muestra que es anterior incluso a los grabados doctrinales de Philip Gallle de 1576, en los que claramente pudo influir. 


\section{LA HARMONIA SEU CONCORDANCIA DECALOGI DE GREUTER}

Esta, hasta ahora poco conocida, serie de grabados fue publicada, según consta en el que hace las veces de portada, por Giovanni Battista Rossi5 en 1653, a partir de los diseños del grabador alsaciano Matthäus Greuter. ${ }^{6}$

Armonía o concordancia del DECÁLOGO con la ORACIÓN DOMINICAL, cuyas SIETE PETICIONES proceden de las SIETE VIRTUDES que se obtienen por los SIETE SACRAMENTOS contra IOS SIETE PECADOS MORTALES, seguidos de lOS SIETE DO-

NES DEL ESPIRITU SANTO para ejercer las SIETE OBRAS DE MISERICORDIA.

Son ocho planchas abiertas por diversos grabadores y dedicada -quizá con motivo de su muerte- al Cardenal Federico Corner fallecido en Roma ese mismo año. ${ }^{7}$

Mateus Greuter ya había creado al menos otra serie referida a los sacramentos para el libro Schemata VII Sacramentorum Sanctae Christi Ecclesiae (Fig. 7) de Gaspare Grispoldi8 (c. 1595-1600) y otra, publicada en Lyon en 1597, bastante relacionada con la que aquí nos ocupa, en la que mostraba conectadas las siete peticiones del Padre nuestro con los siete sacramentos -en escenas figurativas (Fig. 8) de su institución y administración-, y las siete virtudes -tres teologales y cuatro cardinales - representadas en esta ocasión solo por sus objetos o animales simbólicos (cruz, león, ancla, etc. ${ }^{9}$ )

Este empleo didáctico de las imágenes están muy relacionado con lo que sucedía en ese momento en los Países Bajos, lugar en el que Greuter se había formado y del que se fue huyendo de la enorme competencia ${ }^{10}$. Es la época en que los grandes editores y grabadores como Philip Gallé, Plantin, los Wierix, los Sadeler, etc. estaban explotando el mercado existente durante el la segunda mitad del siglo

\footnotetext{
5 Giovanni Battista de Rossi fue miembro de una larga saga de impresores italianos (Giuseppe, Domenico, Giandomenico, etc) con los que Greuter tuvo una fructífera colaboración especialmente en el diseño, fabricación y venta de globos terráqueos. Algunos de los diseños y planchas de Greuter quedaron en propiedad de los Rossi tras su fallecimiento en 1638. Entre ellos debían estar estos que Giovanni Battista mandó grabar y publicó años mas tarde. Cfr. Guerrieri Borsoi, 2002. Existe otra edición copia al aguafuerte probablemente a partir de las mismas planchas, publicada también en Roma por Carlo Losi en 1773. Véase Federici, 2008.

6 Matthäus Greuter (1564-1638) nacido en Estrasburgo, trabajó en Avignon y Lyon antes afincarse a Roma desde 1606 hasta su muerte. Allí estuvo al servicio de diversos papas, nobles y príncipes de la Iglesia y produjo una abundante obra entre la que destacan los grabados arquitectónicos, vistas, mapas, y, sobre todo, los realizados para globos terráqueos. Cfr. Beyer, 2008 y Dahl, Dahl, y Gauvin, 2000, p. 125 y ss.

7 Se trata de Federico Baldissera Bartolomeo Corner, nacido en Venecia en 1579 y fallecido en Roma en junio de 1653. Como señala la dedicatoria que enumera la larga lista de sus títulos, fue cardenal presbítero de Santa Maria del Trastevere -entre 1626-1627- y obispo de Bergamo -entre 1623 y 1626 . Su tío, llamado también Federico Corner, nacido en 1531 y muerto en 1590, al que en PESSCA asignan la dedicatoria, aunque obispo también de Bergamo, fue sin embargo Cardenal bajo el título de San Esteban en Monte Celio desde 1586 hasta su muerte. Por esta confusión se data el diseño de esta serie entre 1585 y 1590, pero debió de realizarse en torno 1627, aunque la publicación se hiciera en 1653 aprovechando quizá el fallecimiento del dedicatario.

8 Cfr. Gallart Pineda, p. 140 y fig. 90

${ }^{9}$ Como se puede ver en PESSCA 3681A/3681B estos grabados también dieron lugar a cuadros doctrinales en virreinato del Perú. La serie sirvió además de base para tablas de los muros de la iglesia de San Miguel Arcángel en Binarowa, una de las hermosas Iglesias de madera de la Pequeña Polonia, declaradas Patrimonio de la Humanidad por la UNESCO en 2003. Véase Łanuszka 2019.

10 Cfr. Dahl, y Gauvin, 2000, p. 125.
} 


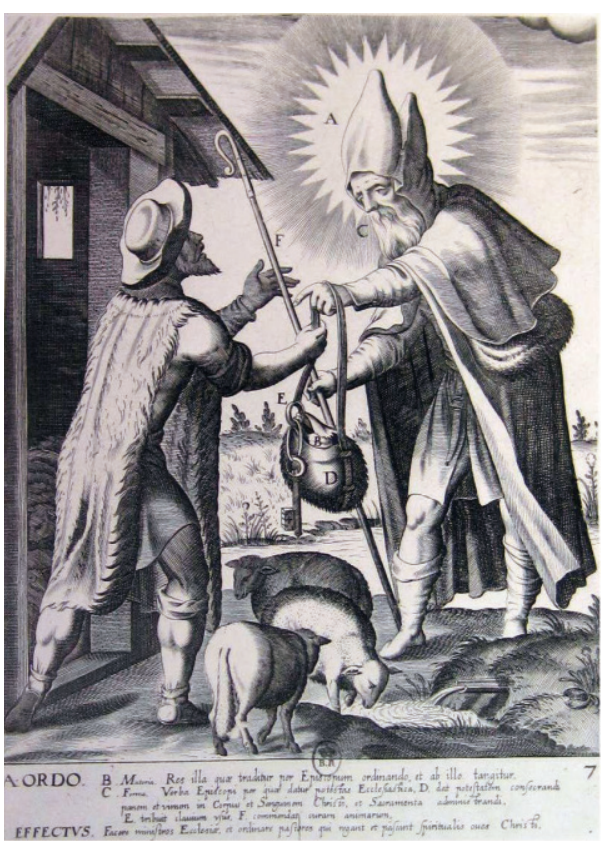

Fig. 7. Greuter, Mateus, Schemata VII Sacramentorum, Lam. VI. Sacramento del Orden

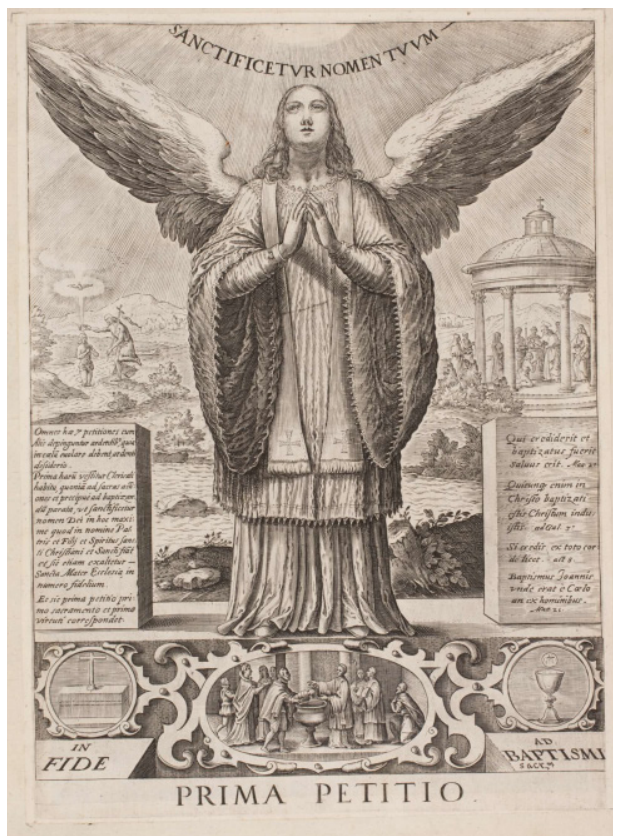

Fig. 8. Greuter, Mateus, VII Petitiones Orationis.. lam. I, Primera petición

XVI y primera del XVII, a raíz del decreto de Trento sobre las imágenes y la aparición de los catecismos tridentinos, especialmente los de Canisio ${ }^{11}$.

Es el momento en que, además de los catecismos ilustrados jesuíticos, que ya mencioné en mi anterior artículo, aparecieron por ejemplo, las conocidas series de grabados doctrinales de Philip Gallé (1576) sobre los sacramentos (Fig. 9) y las obras de misericordia -corporales y espirituales-, y libros como el monumental Icones ad Veridicus christianus (Amberes, Plantin, 1601) del también jesuita Jan David, que incluye grabados para la enseñanza de gran parte de la doctrina cristiana: sacramentos, vicios, virtudes, pecados, etc.

Todas estas obras y autores se pueden encuadrar en el mismo el movimiento que las diversas series de grabados de Greuter -y los cuadros de ellos derivadosrealizadas, primero en Lyon -otro de los grandes centros impresores de la épocay más tarde en Roma en colaboración con los Rossi.

Conviene aclarar también que, aunque los grabadores e impresores y, tras ellos, los pintores compitieran por el mercado de la imagen doctrinal, las posibilidades de representación, en razón de los temas, eran bastante limitadas y venían marcadas por unas doctrinas -como la de Canisio- que determinaban los contenidos y establecían las fuentes. 


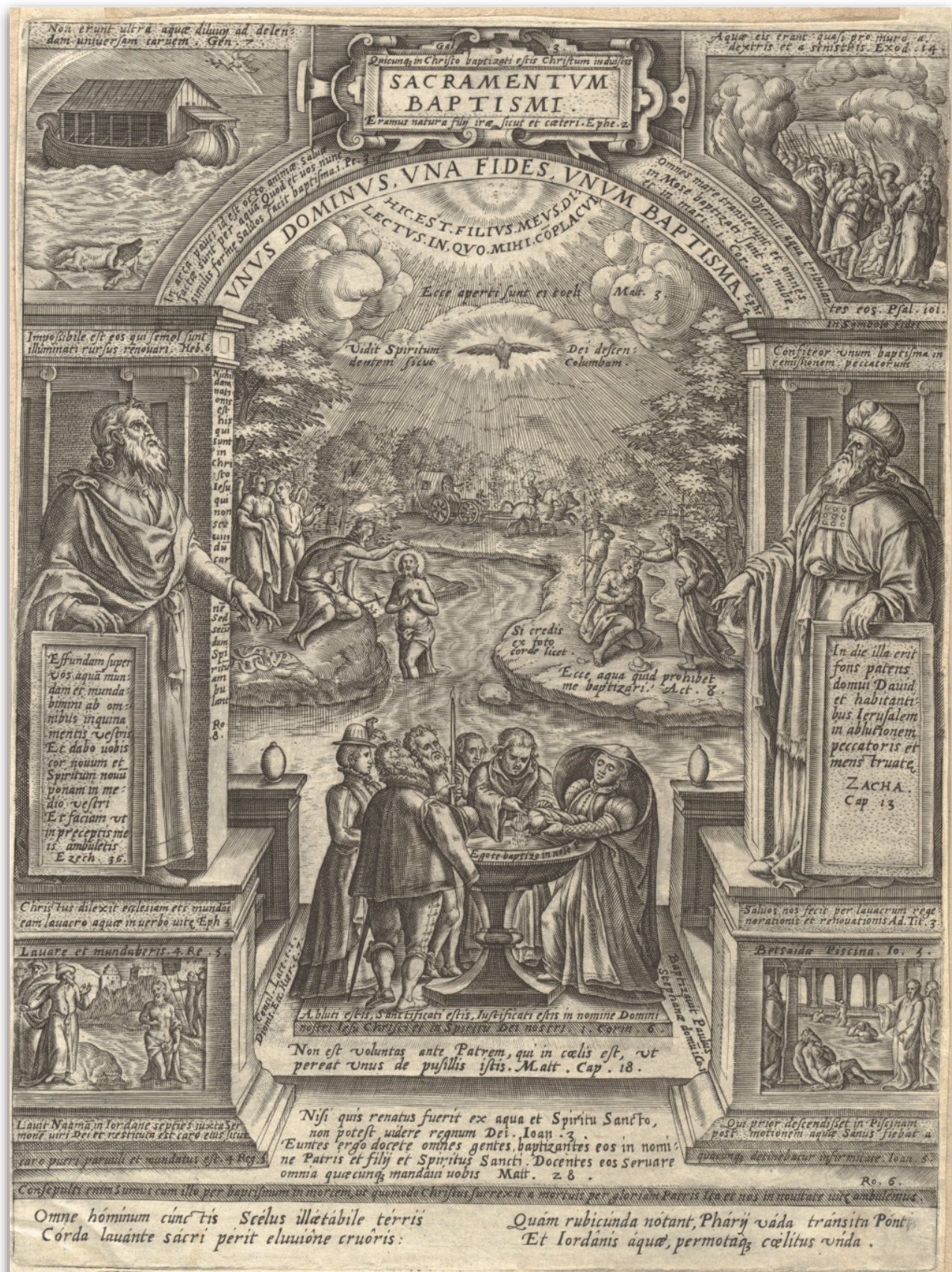

Fig. 9. Philips Galle, Sacramento del Bautismo, Amberes, 1576 


\section{Las cartelas}

Como ya he dicho, de la misma forma que los diversos elementos que componen los grabados de Greuter permiten relacionarlos con las doctrinas ilustradas del momento, las cartelas explicativas que los acompañan los vinculan sin lugar a dudas con la tradición de las siete septenas, que ya traté en mi primer trabajo.

En el esquema doctrinal del Speculum Theologiae de Juan de Metz -muy relacionado con De quinque septenis de Hugo de San Victor ${ }^{12}-$ se vinculaban de modo casi necesario

1. una de las siete peticiones del Padre nuestro,

2. uno de los siete sacramentos,

3. uno de los siete dones del Espíritu Santo,

4. una de las siete armas de la justicia,

5. una de las siete obras de misericordia corporales y otra de las espirituales,

6. una de las siete virtudes principales,

7. uno de los siete pecados capitales.

con unos enlaces - hic, sic, et, ita, ut- que parecen tener una función lógica, aunque realmente establezcan conexiones fundamentalmente retóricas ${ }^{13}$.

Los grabados de Greuter siguen más o menos el mismo esquema, aunque añadiendo los mandamientos y eliminando las armas del cristiano, menos comunes en las doctrinas del momento:

1. un mandamiento del decálogo

2. una de las siete peticiones del Padre nuestro,

3. uno de los siete sacramentos,

4. una de las siete virtudes principales,

5. uno de los siete dones del Espíritu Santo,

6. uno de los siete pecados capitales,

7. una de las siete obras de misericordia corporales.

Aunque la presencia del Decálogo resulte irreconciliable con el esquema septiforme, es tal la fuerza de este esquema que Greuter prefirió mantenerlo aun a costa de tener que colocar el primero de los mandamientos en el grabado que sirve de prólogo, y exponer el octavo, noveno y décimo en el último de ellos. De hecho, los grabados se numeran a partir de los elementos de las septenas, quedando los mandamientos como elemento discordante: el segundo aparece en la primera septena, el tercero en la segunda, y así hasta los tres últimos, que están en la séptima14.

Además, como sucede en la rueda de Juan de Metz, y ya mostré en mi anterior trabajo (p. 612), las asociaciones existentes entre los elementos de cada septena se fijan a partir del Padrenuestro, rompiéndose en algunos casos - sacramentos, vicios, etc.el orden habitual, atendiendo así a criterios otra vez más retóricos que doctrinales.

12 Hugo de san Víctor toma como punto de partida 1) los pecados capitales que vincula con 2) las peticiones del Padre nuestro, 3) los dones del Espíritu Santo, 4) las virtudes del Sermón de la montaña y 5) las bienaventuranzas. Véase al respecto, por ejemplo, Dunning 2016.

13 Véase Spears, 2006, p. 7. Para que pueda apreciarse la similitud del esquema de Juan de Metz con los textos de Greuter reproduzco también una traducción de las siete septenas como apéndice.

14 Incluyo las fórmulas doctrinales completas de las septenas y el Decálogo en el Apéndice I. 


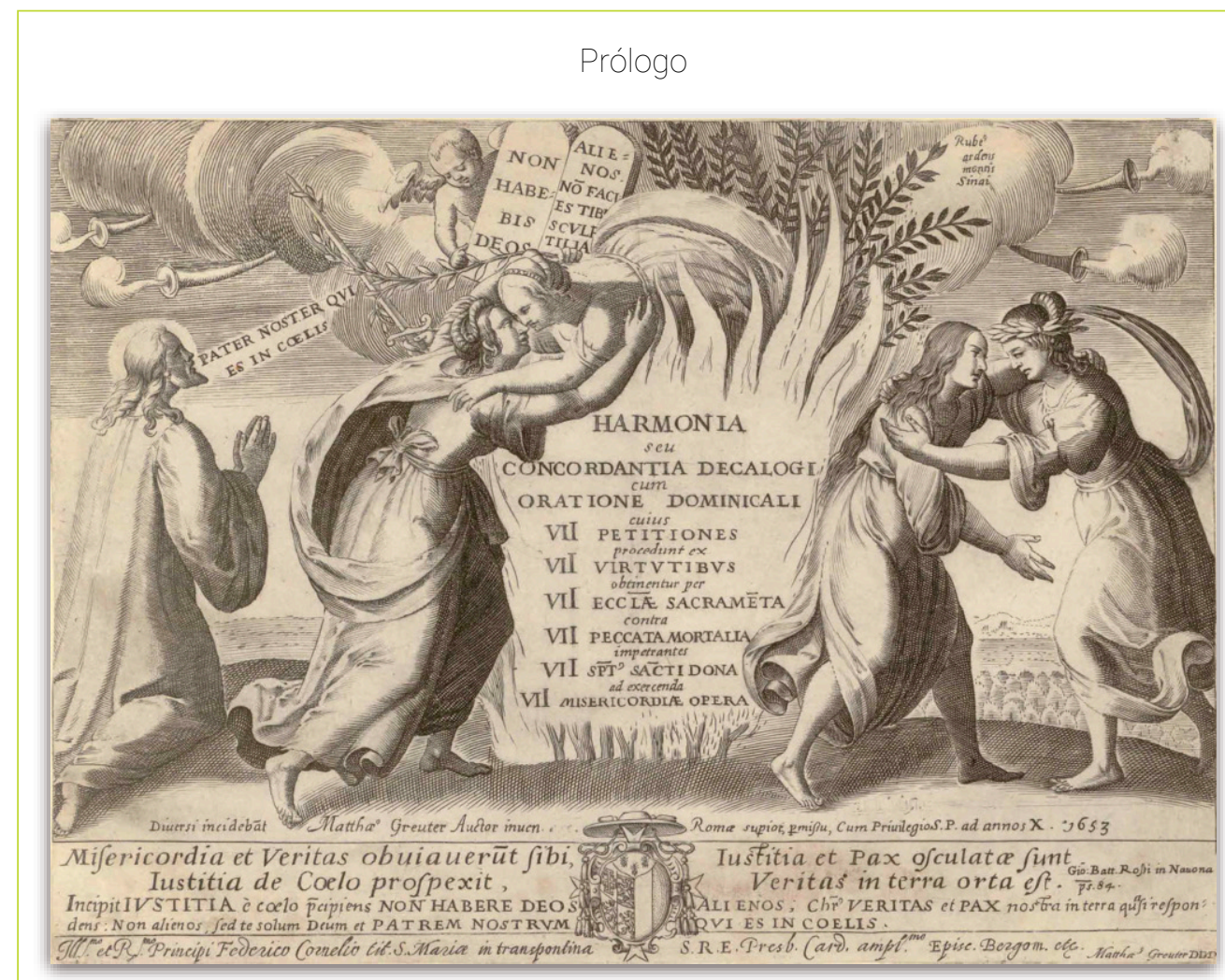

La Misericordia y la Verdad se encontraron, la Justicia y la Paz se besaron la Justicia miró desde el Cielo, la Verdad brotó de la tierra (Salmo 84).

Comienza la JUSTICIA preceptuando desde el cielo: No TENDRÁS DIOSES EXTRANJEROS; Cristo, nuestra VERDAD y PAZ en la tierra, como respondiendo: no solo no extranjeros, sino a ti único Dios y PADRE NUESTRO QUE ESTÁS EN LOS CIELOS ${ }^{13}$.

La cartela del grabado que hace las veces de prólogo y portada -ya que incluye los créditos y la dedicatoria-, inequívocamente ligada al salmo 84, describe la compleja escena y las extrañas figuras femeninas que aparecen en ella. Esta texto confirma pues la descripción que hice del cuadro prólogo de Miguel de Santiago en mi primer trabajo, sin haber tenido acceso al grabado en el que estaba basado.

La explicación que di basándome en las moralidades medievales -en especial las realizadas a partir de los Misterios de Cristo del Pseudo-Buenaventura-, siguen siendo, en mi opinión, válidas también para el grabado. El recurso a las llamadas Cuatro hermanas para establecer el vínculo entre el decálogo -la Justicia-, el Padre nuestro y el resto de las septenas -Verdad y Paz-, puede ser original de esta serie ideada por Greuter o, al menos, yo no he conseguido localizar otra fuente. 


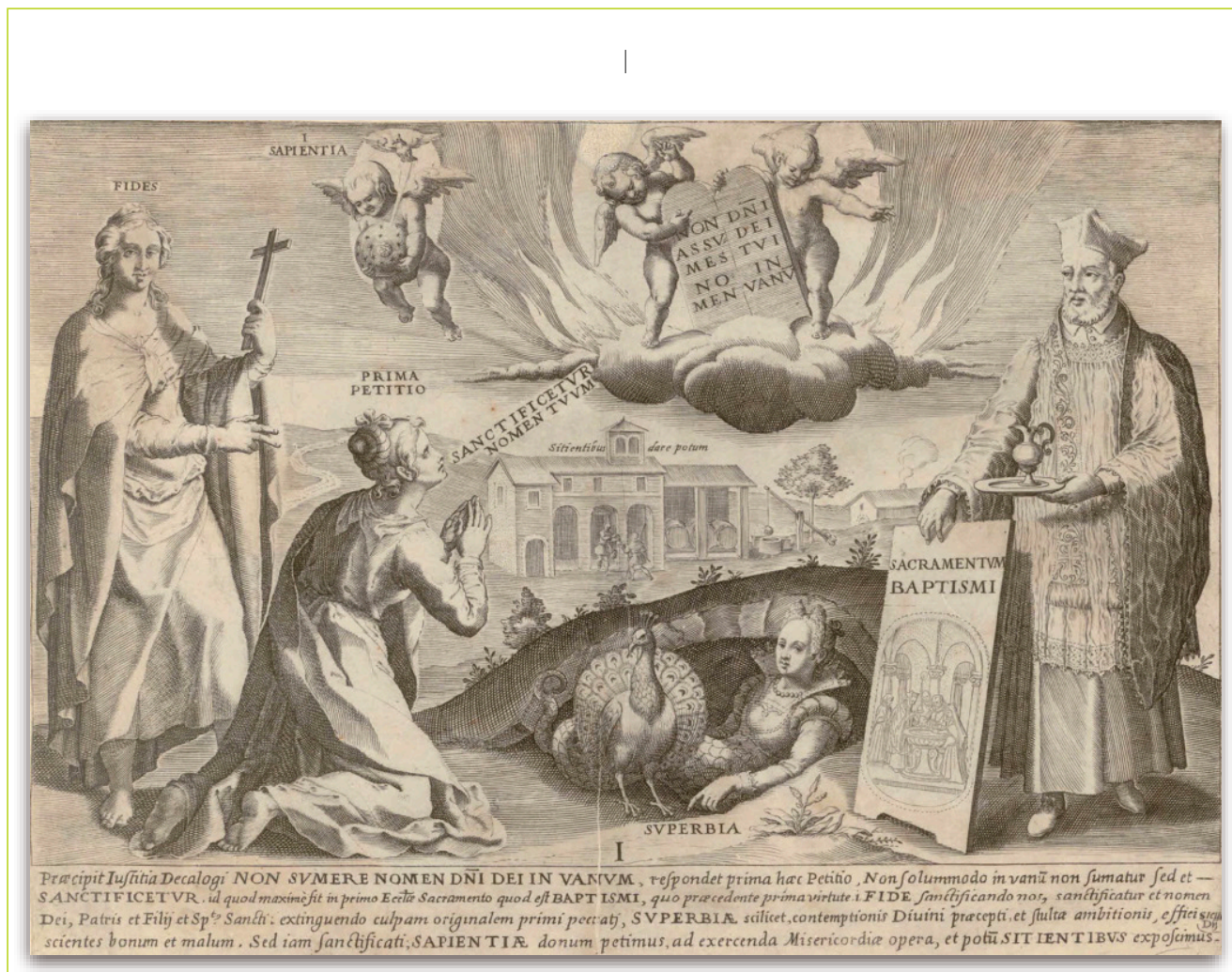

Prescribe la Justicia del Decálogo No tOMARÁs EL NOMBRE DE DIOS EN VANO, responde esta primera petición, no solo no sea empleado en vano, sino también SANTIFICADO, lo cual se hace sobre todo en el primer sacramento de la Iglesia que es el BAUTISMO, por el cual, adelantándose la primera virtud, la FE, santificándonos, es santificado el nombre del Padre, el del Hijo y el del Espíritu Santo; extinguiendo la culpa original del primer pecado - a saber, de SOBERBIA- de desprecio del mandato divino y la necia ambición de hacerse como dioses, conocedores del bien y del mal. Y ya santificados, pedimos el don de SABIDURÍA para ejercer las obras de Misericordia, e imploramos BEBIDA PARA AL SEDIENTO.

La primera septena en la serie grabada por Greuter es idéntica al cuadro de Miguel de Santiago, con la excepción del personaje que administra el sacramento: en el primer caso es un presbítero cualquiera -o un personaje para mi desconocidoy en el segundo, san Francisco de Asís, fundador de la orden a la que pertenece el convento que encargó la serie.

Casi todos los elementos que componen esta primera septena - petición, don, virtud, vicio y sacramento- están en el orden habitual. Sin embargo en lugar de la primera de las obras de misericordia aparece aquí la segunda - dar de beber al sediento-, por su fácil asociación con el agua del bautismo. 


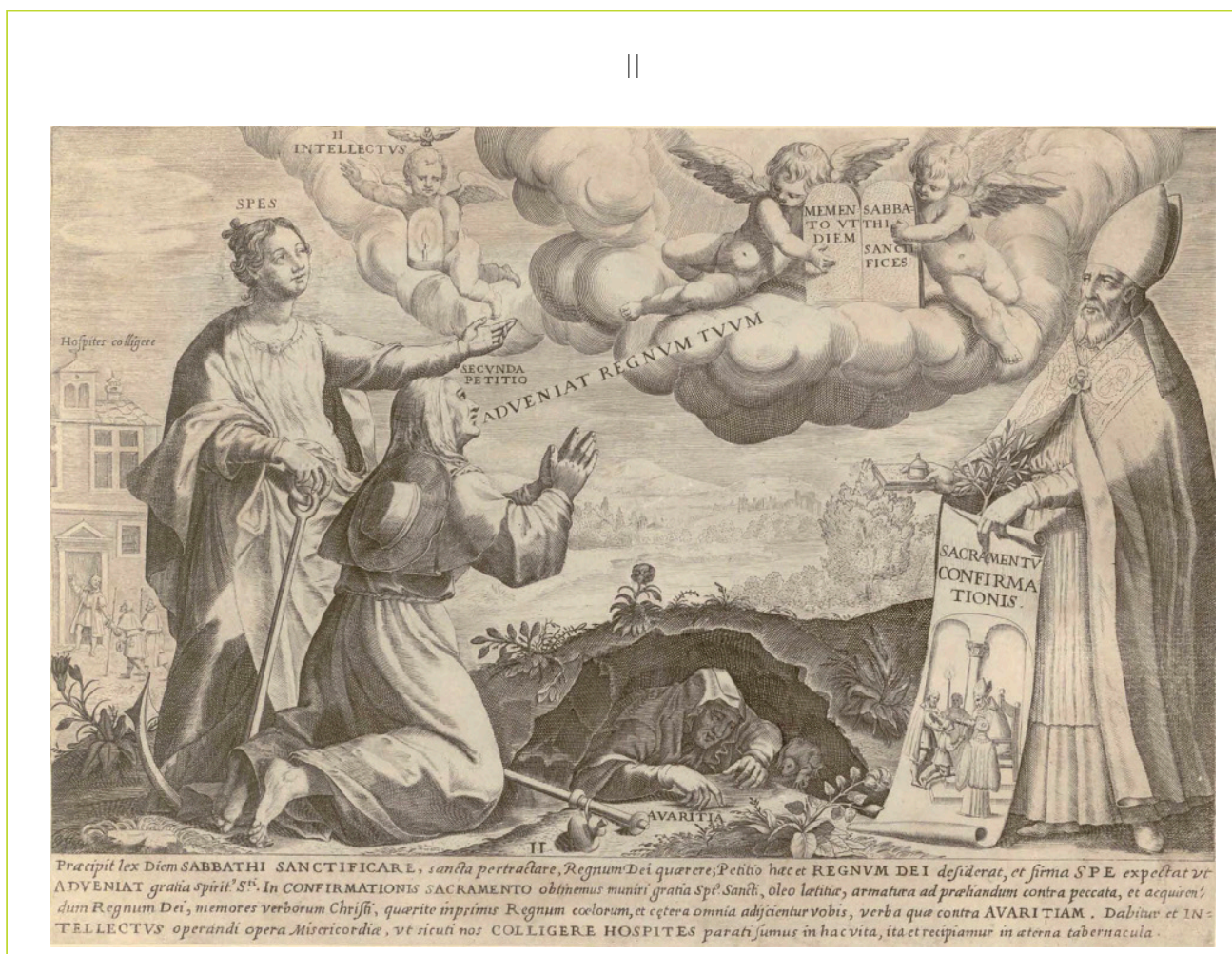

Ordenó la ley SANTIFICAR EL DÍA DEL SÁBADO, dedicarse a las cosas santas, buscar el REINO DE DIOS; esta petición anhela el Reino de Dios, y, con firme ESPERANZA, confía en que venga la gracia del Espíritu Santo. En el SACRAMENTO DE LA CONFIRMACIÓN conseguimos ser fortalecidos por la gracia del Espíritu Santo, aceite de la alegría, armadura para luchar contra los pecados y ganar el Reino de Dios, recordando las palabras de Cristo «buscad primero el Reino de los cielos, y todo lo demás se os dará por añadidura...»; palabras que son contra la AVARICIA. Se dará también la INTELIGENCIA del ejercer obras de misericordia, para que como nosotros estamos preparados en esta vida para ALOJAR A LOS FORASTEROS, así seamos también recibidos en las moradas eternas.

En este grabado correspondiente a la segunda septena, aparece fuera de sitio la sexta obra de misericordia -hospedar a los forasteros-, además, su vinculación con el resto de elementos, que sí están en su posición correcta, es poco consistente. Lo mismo sucede con el tercer mandamiento que está aquí bastante descontextualizado.

En la serie de Miguel de Santiago la oscuridad del cuadro no permitía apreciar con claridad los personajes que representan el pecado capital de la avaricia según la iconografía tradicional y la de los catecismos ilustrados - una mujer con una bolsa de dinero o en actitud de contar, y una rana-. El grabado de Greuter permite confirmar la identificación que hice en su momento a partir de uno de estos catecismos. 


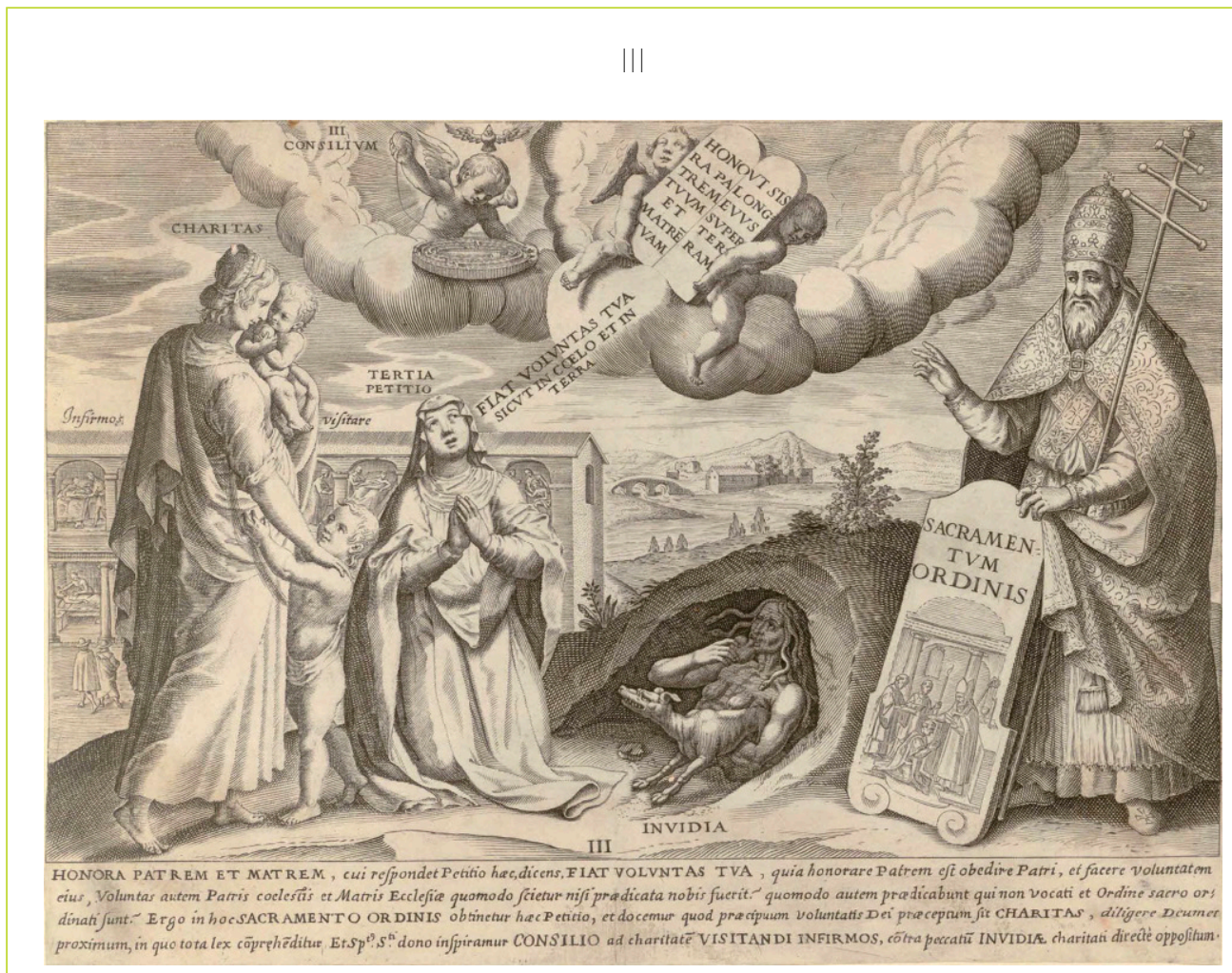

HONRA A TU PADRE Y A TU MADRE, a lo que responde esta petición: HÁGASE TU VOLUNTAD, porque honrar al Padre es obedecer al padre y hacer su voluntad; pero la voluntad del Padre Celestial y de la Madre Iglesia "cómo será conocida si no nos es predicada» y "cómo predicarán los que no son llamados y ordenados con el orden sagrado». Por tanto en este SACRAMENTO DEL ORDEN Se consigue esta petición, y se nos enseña que el principal precepto de la voluntad de Dios es la CARIDAD, amar a Dios y al próximo, en el que está comprehendida toda la ley. Y somos inspirados por el don del Espíritu Santo de CONSEJO para la caridad de VISITAR ENFERMOS, contra el pecado de ENVIDIA directamente opuesto a la caridad.

En la tercera septena son varios los elementos que están desordenados -el sacramento, el vicio y la obra de misericordia-, probablemente por que los que aquí correspondían encajaban mejor en otra septena, como sucede con la lascivia y el vestir al desnudo, pasados a la sexta. Por eso, las asociaciones que se establecen en este grabado son algo inconsistentes, especialmente la que hay entre la petición «Hágase tu voluntad» y el sacramento del Orden que resulta muy forzada.

El Papa que administra el sacramento en el cuadro de Miguel de Santiago podría identificarse con uno de los de la orden franciscana. En el grabado podría tratarse de Urbano VIII, papa reinante 1623 y 1629, años en que Greuter debió idear la serie. 


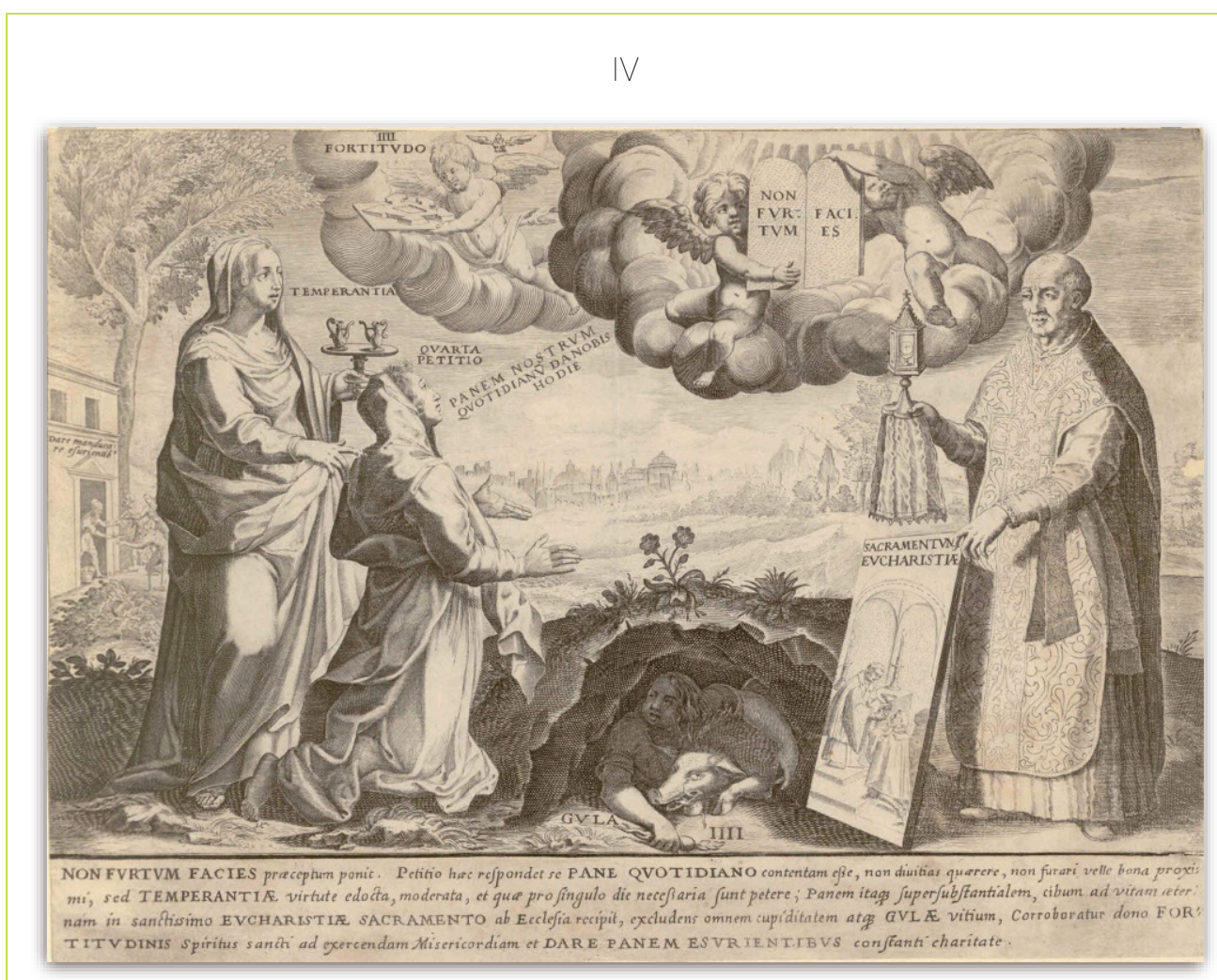

Impone el mandamiento: No HURTES. Esta petición responde que se contenta con el PAN DE CADA DÍA, no busca riquezas, ni quiere hurtar los bienes del próximo, sino pedir, enseñada por virtud de la TEMPLANZA, cosas moderadas y necesarias para cada día. Y así también recibe de la Iglesia el pan supersustancial, alimento para la vida eterna, en el santísimo SACRAMENTO DE LA EUCARISTÍA, rechazando toda concupiscencia y vicio de GULA; es robustecido por el don del Espíritu Santo de FORTALEZA para ejercitar la misericordia y DAR PAN A LOS HAMBRIENTOS con caridad constante.

En este cuarto grabado figuran juntos, con mucho sentido, entre la cuarta petición, la séptima virtud, el cuarto sacramento, el cuarto pecado capital y la primera obra de misericordia, todos ellos relacionados con el alimento corporal y el espiritual. Pero para conseguir esta y otras relaciones se ha retorcido tanto el orden habitual de los elementos, que le toca caer en este grabado al séptimo mandamiento, que está aquí también fuera de lugar.

Como ya expliqué (Zafra, 2020, p. 624), el personaje que administra el sacramento en el cuadro de Miguel de Santiago es probablemente santo Domingo de Guzman. En el grabado de Greuter, en el que está basado el cuadro, quizá pueda tratarse de san Ignacio de Loyola, representado de modo muy similar en algunos cuadros pintados por esos años, como el de los Milagros de San Ignacio de Loyola de Rubens de la iglesia de los jesuitas de Amberes (1617). 


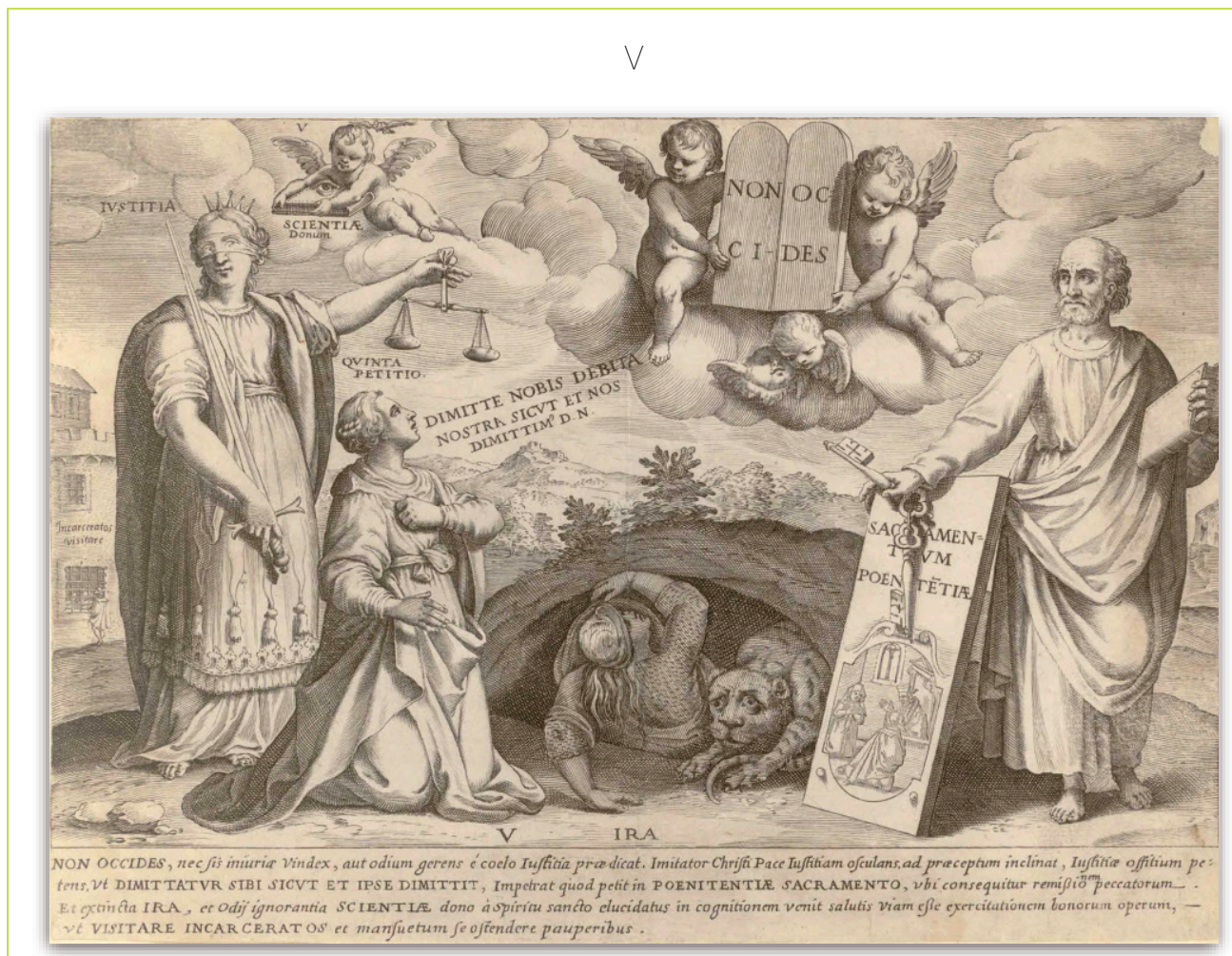

La justicia del cielo manda: NO MATES, ni seas promotor de injurias, ni albergues odio. El imitador de Cristo, el que besa la justicia con la paz, intenta cumplir el precepto pidiendo el favor de la justicia para SER PERDONADO COMO EL MISMO PERDONA, obtiene lo que pide en el sacramento de la PENITENCIA, donde se consigue la remisión de los pecados. Y apagada la IRA y la ignorancia del odio, iluminado por el don del Espíritu Santo de CIENCIA, llega al conocimiento de que el camino de la salvación es el ejercicio de las buenas obras, como VISITAR A LOS ENCARCELADOS y mostrarse manso con los pobres.

El quinto mandamiento, «no matarás», es el único que, junto con el sexto, ocupa su posición correcta integrado en las septenas. Sin embargo algunos de los elementos que se le asocian aquí y con los que sí guarda una cierta relación doctrinal -la justicia, el pecado de ira, la Penitencia o el visitar a los encarcelados - no están en su lugar habitual y han sido traídos desde los que tradicionalmente solían ocupar. Además del citado mandamiento, únicamente pertenecen a esta septena la petición del Padrenuestro, que marca el orden de toda la serie, y el don del Espíritu Santo.

Como detalle curioso, hay que señalar que el león -animal asociado a la iraque pinta Miguel de Santiago en su cuadro está bastante más logrado que esa especie de gato grande que se ve en el grabado Greuter. 


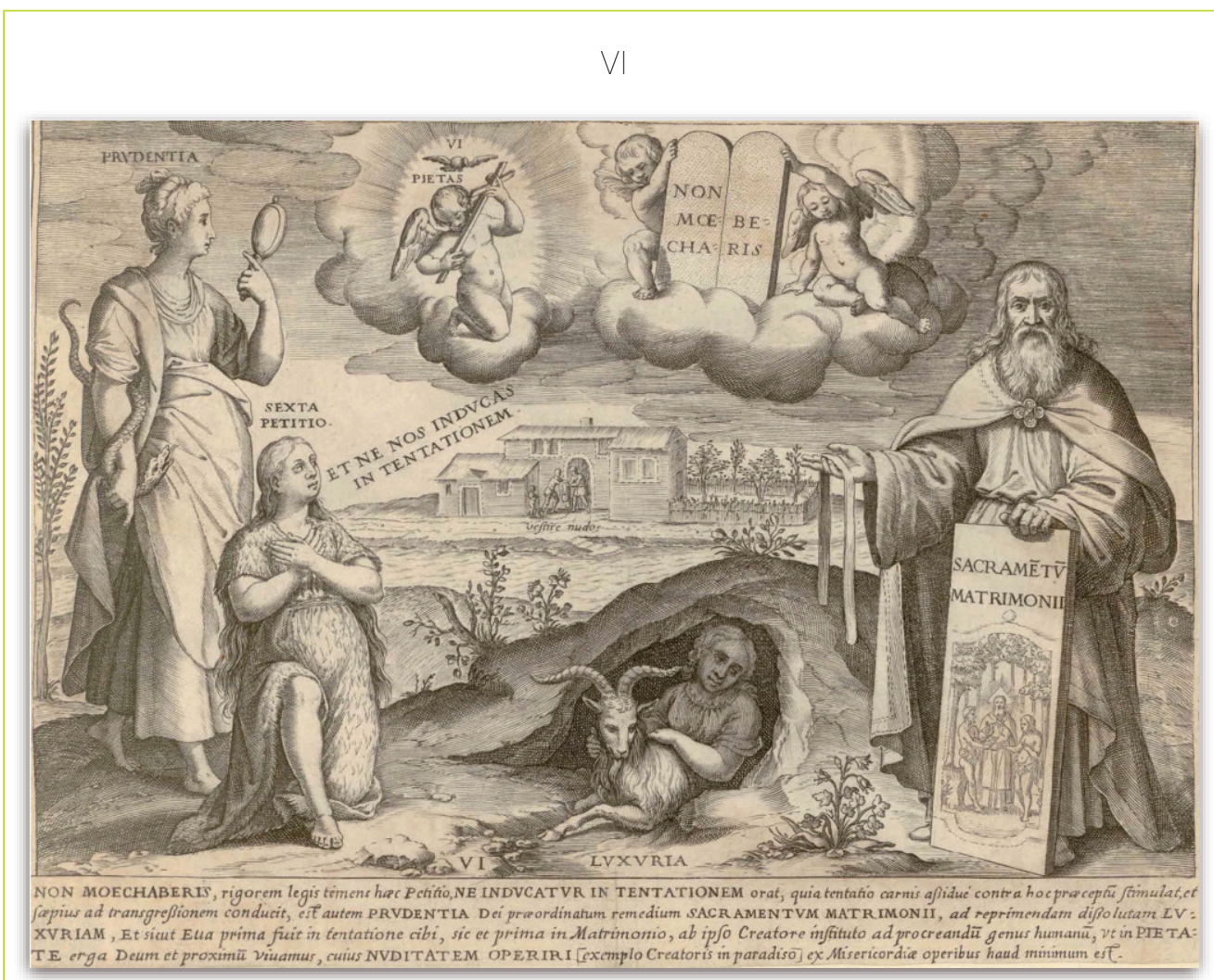

NO FORNICARÁS; temiendo el rigor de la ley esta petición ruega: NO SEA PUESTO EN TENTACIÓN, porque la tentación de la carne constantemente aguijonea contra este precepto, y con mucha frecuencia conduce a su transgresión; pero por PRUDENCIA de Dios es el remedio previsto el SACRAMENTO DEL MATRIMONIO, para reprimir la LUJURIA desordenada. Y como Eva fue primera en la tentación del bocado, así es primera en el matrimonio, instituido por el mismo Creador para la procreación de la raza humana, a fin de que vivamos en la PIEDAD para con Dios y el próximo, cuya DESNUDEZ CUBRIR (a ejemplo del Creador en el Paraíso) nos es la menor de las obras de misericordia.

Esta septena es, con mucho, la más lograda. Aunque se ha movido el sacramento, el mandamiento y la petición están en su posición correcta. Todos los elementos están vinculados temáticamente entre sí, de manera que pudiera parecer que fueron así dispuestos por la doctrina: la lujuria y el adulterio como pecados capital y actual, la desnudez como principal tentación y causa de caída -con la Magdalena como ejemplo-, el matrimonio y el amor como remedio, el propio Dios prudente como co-administrador del sacramento.

Da la sensación de que Greuter estableció primero esta septena y dispuso después el resto mediante relaciones más o menos logradas de manera que ésta no se rompiera. 


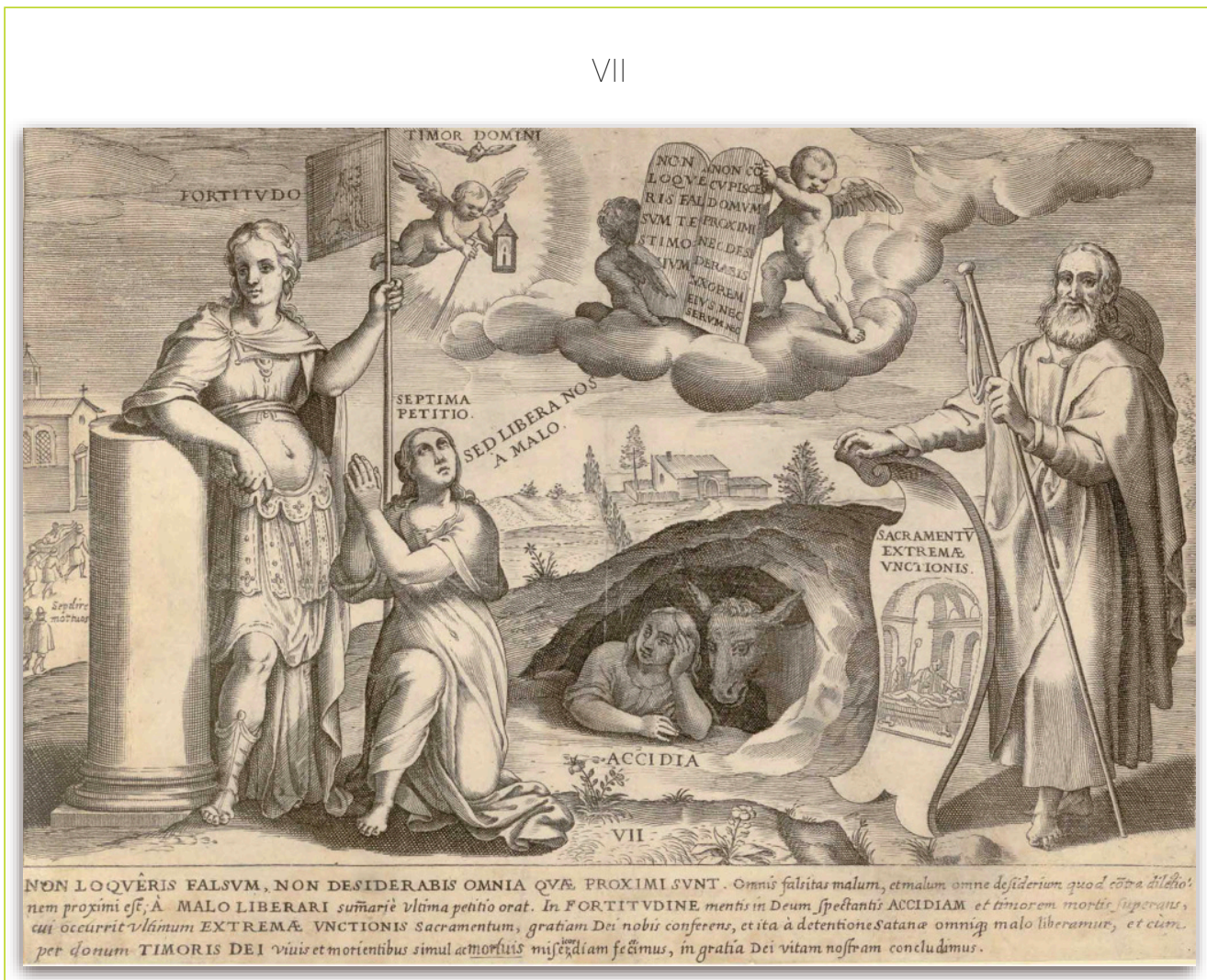

NO DIRÁS FALSEDAD, NO DESEARÁS NADA QUE SEA DEL PRÓXIMO. Toda falsedad es mala, y malo todo deseo que sea contra el amor al próximo. SER LIBRADOS DEL MAL ruega en suma la última petición; superando, con la FORTALEZA del alma que espera en Dios, la ACIDIA y el temor de la muerte, contra el que se opone el ultimo sacramento de la EXTREMA UNCIÓN, que nos confiere la gracia de Dios; y así somos libres de los obstáculos de Satanás y de todo mal, y habiendo ejercido la misericordia por el don de TEMOR DE DIOS, con los vivos, los moribundos y LOS MUERTOS, concluyamos nuestra vida en gracia de Dios.

Entre las aceptablemente logradas está la séptima y última, en la que, gracias quizá al carácter conclusivo de cada elemento, se consigue una cierta relación con las postrimerías y la muerte. Sin embargo la discordancia entre el decálogo y el resto de fórmulas obliga a acumular e insertar en este grabado los tres últimos mandamientos, que no están temáticamente vinculados con el conjunto.

El personaje que porta el escudo del sacramento de la Extrema unción, poco parecido al que aparece en el cuadro de la serie de Quito, muestra, sin embargo, también los distintivos tradicionales - capa, bastón y sombrero de viaje- del apóstol Santiago, a quien siempre se suele atribuir el primer testimonio de ese sacramento (Sant. 5, 14-15). 
Si comparamos las asociaciones establecidas por Greuter entre las distintas series doctrinales con las que hizo Juan de Metz en su rueda de las siete septenas (pueden verse en el apéndice II) se puede apreciar que, aunque en algunos casos estén más logradas estas últimas, en general son bastante similares y resultan ambas más bien forzadas.

El intento de coordinar los elementos de las diversas septenas, en que se había intentado sintetizar la doctrina cristiana con fines mnemotécnicos aprovechando el valor simbólico del siete, no tuvo demasiado éxito.

Esto explica tanto la poca influencia posterior tanto de la Rueda de las siete septenas como de esta serie de grabados en ella basados. La fuerza de la fijación de estas septenas posiblemente impidió que tuvieran éxito unas nuevas fórmulas que hasta cierto punto las rompían.

\section{CONCLUSIÓN}

El estudio de las cartelas de la serie de Greuter no añade mucho al análisis iconográfico-doctrinal que hice de los cuadros de Miguel de Santiago, más allá de reafirmar su vinculación con la tradición de las septenas y confirmar algún detalle de difícil visualización o interpretación. Greuter primero y Miguel de Santiago después, asociaron los contenidos de las siete septenas las correspondientes imágenes conceptuales ${ }^{16}$ que figuraron en las doctrinas ilustradas a partir de Belleri, intentando crear un nuevo recurso que atrajese la atención del gran movimiento catequético que se estaba dando en su tiempo.

Algo similar puede comprobarse si se compara (fig. 10) la serie de grabados sobre el Credo de Johan Sadeler y Maarten de Vos que Miguel de Santiago tomó como base al pintar sus cuadros para la Catedral de Bogota, con las estampas correspondientes en el catecismo de Belleri. ${ }^{17}$ Tanto en los grabados de Sadeler-de Vos como en las pinturas en ellos basadas - que también carecen de las cartelas explicativas- puede apreciarse una cierta dependencia formal, pero sobre todo temática respecto de los los grabados de Belleri.

Se puede decir que estos - sobre todo la doctrina en ellos encerrada- son la base de la series de Sadeler-de Vos y de la de Miguel de Santiago. Las estampas de este catecismo y de todos los que lo siguieron no son imágenes narrativas - La creación de Eva o La visión de Ezequiel, por ejemplo- sino fundamentalmente conceptuales, emblemas doctrinales construidos para ayudar a fijar en la mente el dogma que esas escenas representan o anticipan -Creo en Dios Padre omnipotente, creador del cielo y de la tierra, o Creo en la resurrección de la carne-.

Dejar de lado el significado más profundo de estas imágenes, centrándose sobre todo en los aspectos formales, aun cuando permita establecer relaciones correctas, es aislarlas de la cultura en que nacieron y les dio sentido, lo que impide a veces captar lo que en realidad son.

16 Sobre las imágenes conceptuales y narrativas véase García Mahíques, 2011

${ }^{17}$ Ambas series pueden verse en PESSCA 720A/720B a 730A/730B. Véase también Fajardo de Rueda, 2011. 

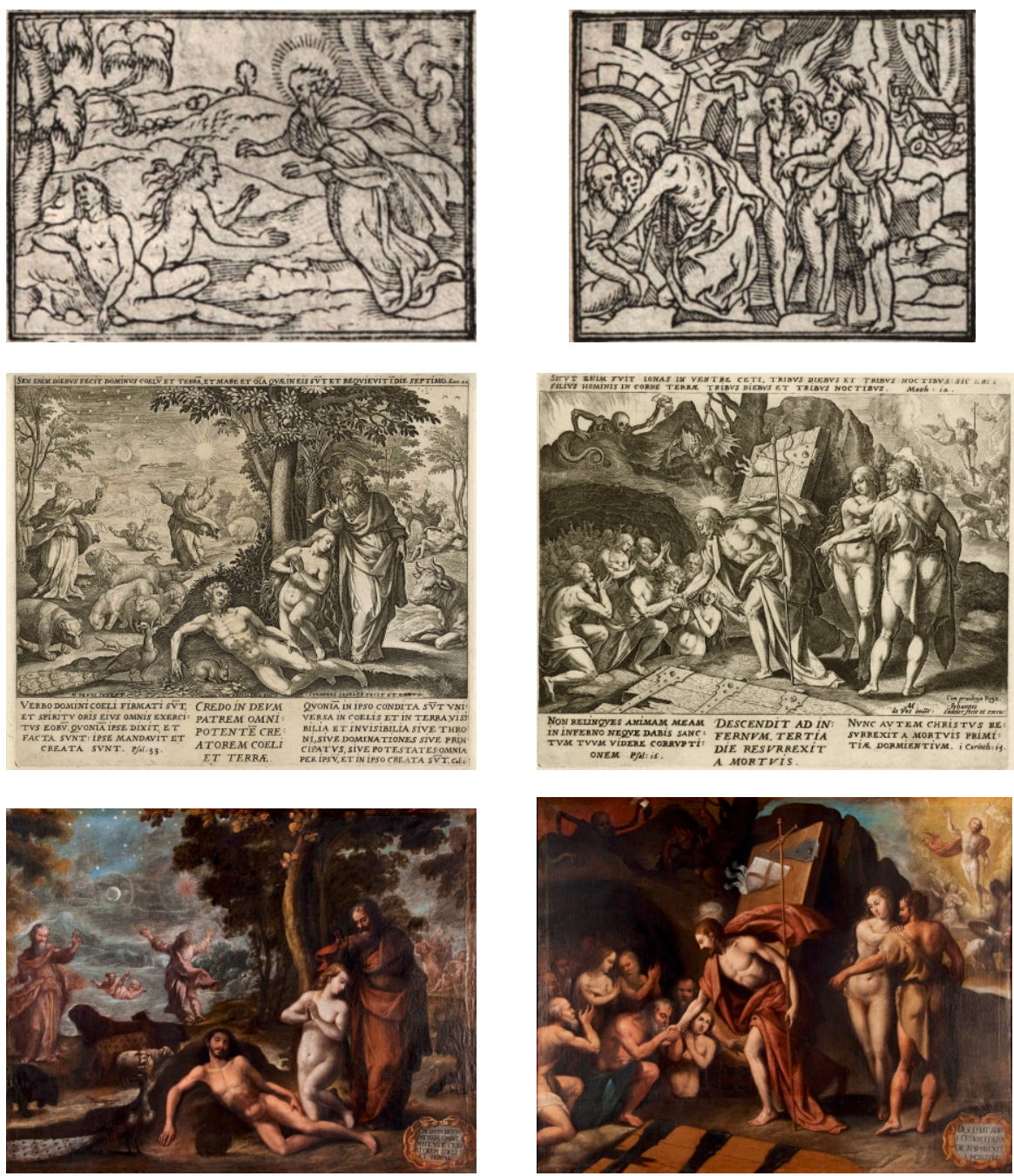

Fig. 10. Primer y quinto artículos del Símbolo de la Fe el catecismo de Belleri, 1575, en la series de grabados de Johan Sadeler y Maarten de Vos, (1579) y en el Credo de Miguel de Santiago para la Catedral de Bogotá (c. 1690) 


\section{BIBLIOGRAFÍA}

Beyer, Victor. s. f., «Greuter, Matthias», en Nouveau dictionnaire de biographie alsacienne, vol. 13, p. 1282. También en https://www.alsace-histoire.org/netdba/ greuter-greuther-matthias/. Fecha de acceso: 21 de abril de 2021.

Canisio, Pedro, Doctrina cristiana, ed. Rafael Zafra, Palma de Mallorca, José de Olañeta / Ediciones UIB, 2014.

Canisio, Pedro, Institutiones christianae pietatis seu parvus Catechismus catholicorum, Antuerpiae, Bellerus, 1575.

Dahl, Edward y Jean-François Gauvin, Sphaerae Mundi, Montreal, McGill-Queen's University Press, 2000.

David, Jan, Veridicus Christianus, Antuerpiae, Ex officina Plantiniana, apud Ioannem Moretum, 1601.

Dunning, Andrew, «Hugh of Saint Victor's De quinque septenis and Its Versification in Samuel Presbiter's De oratione dominica», en The Annual of the Association for Documentary Editing 37, 2016. https://scholarlyediting.org/2016/editions/intro.dunning.html. Fecha de acceso: 15/02/2021

Fajardo de Rueda, Marta, «Del grabado europeo a la pintura americana. La serie El Credo del pintor quiteño Miguel de Santiago», HiSTOReLo. Revista de historia regional y local, 3.5, 2011, pp. 191-214.

Federici, Veronica, "Carlo Losi editore "Ai Condotti"», en Giovanna Sapori y Sonia Amadio (eds.), II Mercato delle Stampe a Roma XVI-XIX secolo, Roma, EdicitEditrice Centro Italia, 2008, pp. 95-115.

García Mahíques, Rafael, «Imagen conceptual e imagen narrativa», en Javier Azanza y Rafael Zafra, Emblemática trascendente: hermenéutica de la imagen, iconología del texto, Pamplona, Universidad de Navarra, 2011, pp. 65-86.

Grelle Iusco, Anna, Indice delle stampe intagliate in rame a bulino e in acqua forte esistenti nella stamperia di Lorenzo Filippo De' Rossi: contributo alla storia di una stamperia romana, Roma, Artemide, 1996.

Grispoldi, Gaspare, Schemata VII. Sacramento[rum] sanctae christi ecclesiae quibus materia et forma vna cum effectu ipsorum proprijs. Iconibus figuratur, Lion, 1595.

Guerrieri Borsoi, Maria Barbara, Dizionario Biografico degli Italiani, vol. 59, 2002.

Holstein's German engravings, etchings and woodcuts, ca. 1400-1700, Vol XII, Tilman Falk (ed.), Robert Zijlma (comp.), Amsterdam, M. Hertzberger, 1954.

Łanuszka, Magdalena, «Temptation in Short Dress», Posztukiwania (blog), 15 de septiembre de 2019. http://en.posztukiwania.pl/2019/09/15/temptation-inshort-dress/.

Ojeda, Almerindo, Proyecto para las Fuentes Grabadas del Arte Colonial Español (PESSCA). 2005-2021, https://colonialart.org. Fecha de acceso: 21/02/2021.

Spears, Sam, «The Visual Dynamics of the Wheel of Sevens in the Speculum theologiae», web de la Beinecke Library Yale University sobre el Speculum theologiae, 2006. http://beinecke.library.yale.edu/speculum/2v-wheel-of-sevens.html. Fecha de acceso: 25/02/2021.

Zafra Molina, Rafael, «Fuentes y función de la Doctrina cristiana de Miguel de Santiago para el convento de San Francisco de Quito», Hipogrifo. Revista de literatura y cultura del Siglo de Oro, 8.1, 2020, pp. 601-637. 


\section{APÉNDICE I: FóRMULA HABITUAL DE LAS SEPTENAS EN LAS DOCTRINAS Y CATECISMOS *}

\section{Decálogo: Mandamientos de la Ley}

1. Yo soy el señor Dios tuyo - No tendrás dioses extraños en mi presencia; no harás para ti obra de talla con el fin de adorarla.

2. No nombrarás en vano al Señor Dios tuyo.

3. Acuérdate de santificar el día de Sábado.

4. Honra a tu padre y a tu madre, para que vivas largos años sobre la tierra, que darte ha el Señor Dios tuyo.

5. No matarás.

6. No fornicarás.

7. No hurtarás.

8. No dirás falso testimonio contra tu próximo.

9. No codiciarás la mujer de tu prójimo.

10. Ni tampoco su casa, ni la heredad, ni el esclavo, ni la esclava, ni el buey, ni el jumento, ni otra cosa alguna de las suyas.

\section{$2^{\mathrm{a}}$ septena: peticiones del Padre nuestro}

1. Padre nuestro que estás en los Cielos, santificado sea el tu nombre.

2. Venga a nos el tu reino.

3. Hágase tu voluntad, así en la tierra como en el cielo.

4. El pan nuestro de cada día dánosle hoy.

5. Y perdónanos nuestras deudas, así como nosotros perdonamos a nuestros deudores.

6. Y no nos dejes caer en la tentación.

7. Mas líbranos del mal. Así sea.

\section{$4^{\mathrm{a}}$ septena: Virtudes}

1. Fe.

2. Esperanza.

3. Caridad.

4. Prudencia.

5. Justicia.

6. Templanza.

7. Fortaleza.

$6^{\mathrm{a}}$ septena: Dones del Espíritu Santo

1. Don de sabiduría.

2. Don de entendimiento.

3. Don de consejo.

4. Don de ciencia.

5. Don de fortaleza.

6. Don de piedad.

7. Don de temor de Dios.

\section{$3^{\mathrm{a}}$ septena: Sacramentos}

1. Bautismo

2. Confirmación.

3. Eucaristía.

4. Penitencia.

5. Extremaunción.

6. Orden.

7. Matrimonio.

\section{$5^{\mathrm{a}}$ septena: Pecados capitales}

1. Soberbia.

2. Avaricia.

3. Lujuria.

4. Envidia.

5. Gula

6. Ira.

7. Pereza.

$7^{\mathrm{a}}$ septena: obras de misericordia corporales

1. Dar de comer al hambriento.

2. Dar de beber al sediento.

3. Vestir al desnudo.

4. Redimir al cautivo.

5. Visitar a los enfermos.

6. Dar posada al peregrino.

7. Enterrar a los muertos.

\footnotetext{
* Reproduzco estas fórmulas de la doctrina cristiana a partir de la traducción castellana del catecismo breve de san Pedro Canisio, máxima expresión de la catequética de la Compañía de Jesús y una de las más extendidas en mundo católico. Véase al respecto el estudio introductorio de Canisio, Doctrina cristiana, 2014 edición de la que está tomado también el texto (pp. 207-243). La redacción que emplea Greuter tanto en los grabados como en las cartelas es bastante cercana al original latino de Canisio.
} 


\section{APÉNDICE II: RUEDA DE LAS SIETE SEPTENAS}

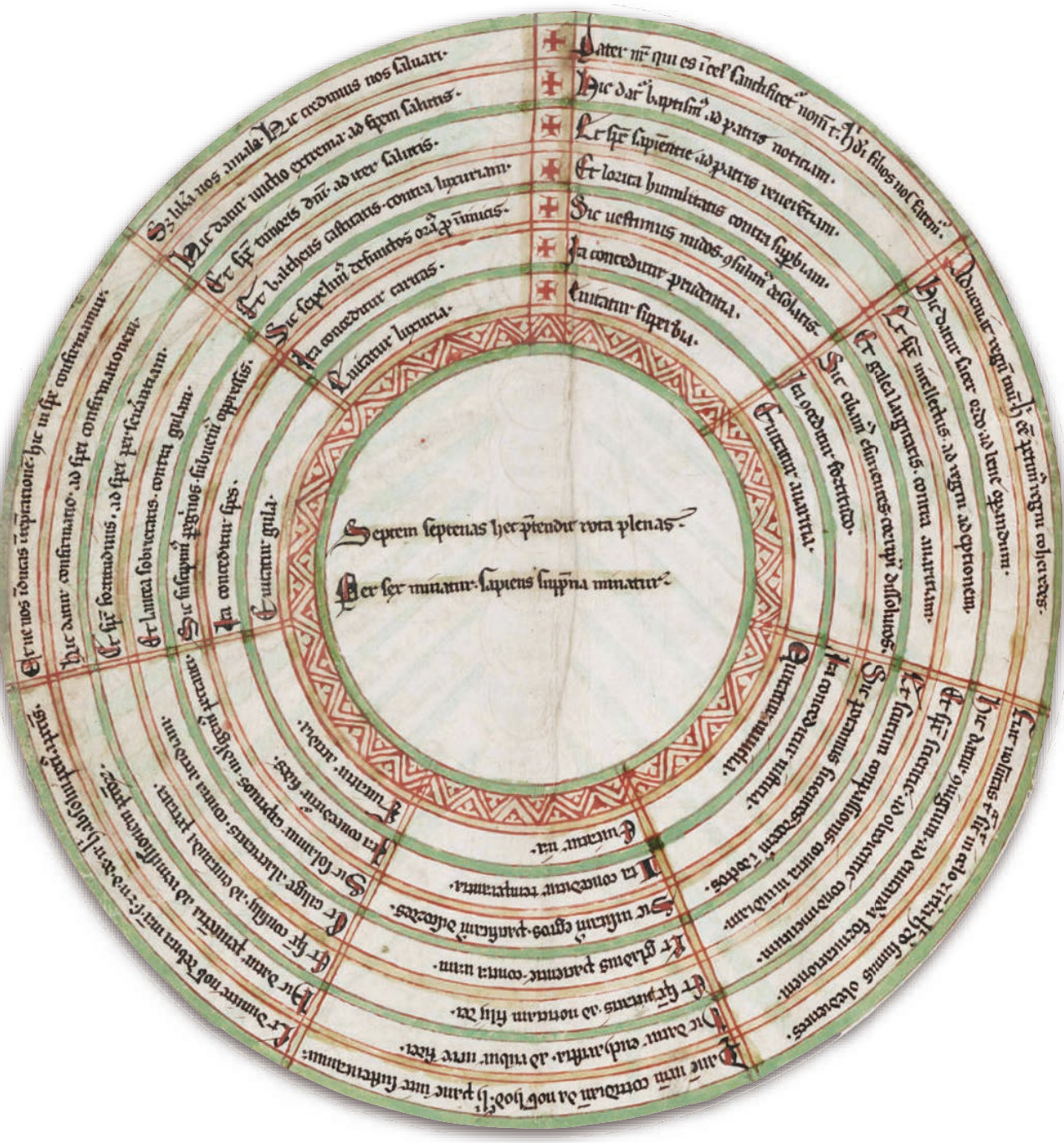

Septem septenas haec praetendit rota plenas. Per sex minatur sapiens superna minaturus
Esta rueda muestra las siete septenas completas. A través de seis es conducido el sabio que ha de ascender mediante la superior 
I PATER NOSTER, QUI EST IN CELIS, SANTIFICETUR NOMEN TUUM. Hic domini filios nos fatemur. Hic datur BAPTISMA ad Patris notitiam. Et spiritus SAPIENTIE ad Patris reverentiam. Et lorica HUMILITATIS contra SUPERBIAM. SiC VESTIMUS NUDOS, CONSULIMUS DESOLATIS. Ita conceditur PRUDENTIA.

Evitatur SUPERBIA

II AdVENIAT REgNUM TUUM. Hic esse petimus regni coheredes.

Hic datur SACER ORDO ad bene operandum. Et spiritus INTELLECTUS ad regni adeptionem. Et galea LARGITATIS contra AVARITIAM. SiC CIBAMUS ESURIENTES, CORRIPIMUS DISSOLUTOS. Ita conceditur FORTITUDO.

Evitatur AVARITIA.

III Fiat Voluntad TUA SiCUt IN COELO ET IN TERRA. HiC Domino sumus obedientes.

Hic datur CONIUGIUM ad eviatandam fornicationem. Et spiritum SCIENTIAE ad obedientiae condimentum. Et SCUtum COMPASIONIS contra invidiam. SiC POTAMUS SICIENTES, DOCEMUS INDOCTOS. Ita conceditur IUSTITIA. Evitatur INVIDIA.

IV PANem Nostrum COTIDIANUM DA NOBIS HODIE. HiC Pane vitæ sustentamur.

Hic datur EUCHARISTIA ad rubur vere fidei.

Et spiritus PIETATIS ad notitiam filii Dei

Et gladius PATIENTIAE contra iram.

SiC VISITAMUS EGROS, PACIFICAMUS DISCORDES.

Ita conceditur TEMPERANTIA.

Evitatur IRA.

$\checkmark \quad$ ET DIMITE NOBIS DEBITA NOSTRA SICUT ET NOS DIMITIBUS DEBITORIBUS NOSTRIS. Hic absolvi petimus a pecatis. Hic datur PENITENTA ad remissionem pecatorum.

Et spiritum CONSILII ad evitanda peccata.

Et calige ALACRITATIS contra accidiam.

Sic SOLAMUR CAPTIVUS, INDULGENTE PECCANTI.

Ita conceditur FIDES.

Evitatur ACCIDIA.

VI ET NE NOS INDUCAS IN TEMPTATIONEM. Hic in SPE confirmamur.

Hic datur CONFIRMATIO ad spei confirmationem. Et spiritum FORTITUDINIS ad spei perserverantiam.

Et lancea SOBRIETATIS contra gulam.

SiC SUSCIPIMUS PEREGRINOS SUBVENIMUS OPPRESSIS.

Ita conceditur SPES.

Evitatur GULA.

VII Sed liberanos a malo. Hic credimus nos salvari. Et datur UNCTIO EXTREMA ad spem salutis.

Et spiritus TIMORIS DOMINI ad iter salutis.

Ut baltheus CASTITATIS contra luxuriam.

SiC SEPELIMUS DEFUNCTOS, ORAMUS PRO INIMICIS.

Ita conceditur CARITAS.

Evitatur LUXURIA.
PADRE NUESTRO QUe ESTÁS EN EL CIELO, SANTIFICADO SEA TU NOMBRE: Aquí nos confesamos hijos del señor.

Aquí se da el BAUTISMO para el conocimiento del Padre.

Y el espíritu de SABIDURÍA para reverencia del Padre.

Y la coraza de la HUMILDAD contra la SOBERBIA.

Así VESTIMOS A LOS DESNUDOS, CONSOLAMOS A LOS DESOLADOS. Así se concede la PRUDENCIA.

Se evita la SOBERBIA.

VENGA A NOSOTROS TU REINO: Aquí pedimos ser herederos del reino.

Aquí se da el ORDEN SAGRADO para obrar bien.

Y espíritu de ENTENDIMIENTO para la consecución del reino.

Y el yelmo de la GENEROSIDAD contra la AVARICIA.

Así alimentamos a los HAMBRIENTOS; corregimos a los disolutos.

Así se concede la fortaleza.

Se evita la avaricia.

HÁGASE TU VOLUNTAD EN LA TIERRA COMO EN EL CIELO. Aquí somos obedientes al Señor.

Aquí se da el MATRIMONIO para evitar la fornicación.

Y el espíritu de CONOCIMIENTO para sazonar la obediencia.

Y el escudo de la compasión contra la envidia.

Así, DAMOS DE BEBER A LOS SEDIENTOS; ENSEÑAMOS A LOS IGNORANTES.

Así se concede la JusticiA.

Se evita la ENVIDIA.

DANOS HOY NUESTRO PAN DE CADA DÍA. Aquí somos sustentados por el pan de vida.

Aquí se da la EuCARISTía para fortaleza de la fe verdadera.

Y el espíritu de PIEDAD para el conocimiento del hijo de Dios.

Y la espada de la PACIENCIA contra la ira.

ASÍ, VISITAMOS A LOS ENFERMOS; PACIFICAMOS A LOS DISCORDES.

Así se da la TEMPLANZA.

Se evita la IRA.

PERDONA NUESTRAS DEUDAS COMO NOSOTROS PERDONAMOS NUES-

TROS DEUDORES. Aquí pedimos ser absueltos de los pecados.

Aquí se da la PENITENCIA para la remisión de los pecados.

Y el espíritu de CONSEJo para evitar los pecados.

Y las botas de la ALEGRÍA contra la acidia.

ASí CONSOLAMOS A LOS CAUTIVOS; PERDONAMOS AL PECADOR.

Así se da FE.

Se evita la ACIDIA.

Y NO NOS PONGAS EN TENTACIÓN. Aquí SOmos confirmados en la ESPERANZA.

Aquí se da la CONFIRMACIÓN para la confirmación de la esperanza Y el espíritu de FORTALEZA para perseverar en la esperanza.

Y la lanza de la SOBRIEDAD contra la glotonería.

Así RECIBIMOS A LOS PEREGRINOS; AYUDAMOS A LOS OPRIMIDOS

Así Se da ESPERANZA.

Se evita la GULA.

SINO LíBRANOS DEL MAL. Aquí creemos que nos salvamos. Aquí se da la EXTREMAUNCIÓN para la esperanza de la salud.

Y el espíritu de TEMOR DEL SEÑOR para el camino de la salvación.

Y el ceñidor de la castidad contra la lujuria.

Así enterramos a los muertos; oramos por los enemigos. Así se da caridad.

Se evita la lujuria. 